Mater. Res. Soc. Symp. Proc. Vol. 1741 @ 2015 Materials Research Society

DOI: 10.1557/opl.2015.189

CORRIGENDUM

\title{
Dislocation Mobilities in GaN from Molecular Dynamics Simulations- CORRIGENDUM
}

N. Scott Weingarten

doi: 10.1557/opl.2015.25, Published by Materials Research Society, 02 February 2015.

The original Figure 4 published in this paper is incorrect. Below is the correct figure, as well as updates to the surrounding text regarding this figure:

Page 3, in section "c-type edge dislocations":

There are two slip systems for $c$-type dislocations, $\{\overline{1} \overline{1} 20\}\langle 0001\rangle$ and $\{1 \overline{1} 00\}\{0001\rangle$.

Page 4:
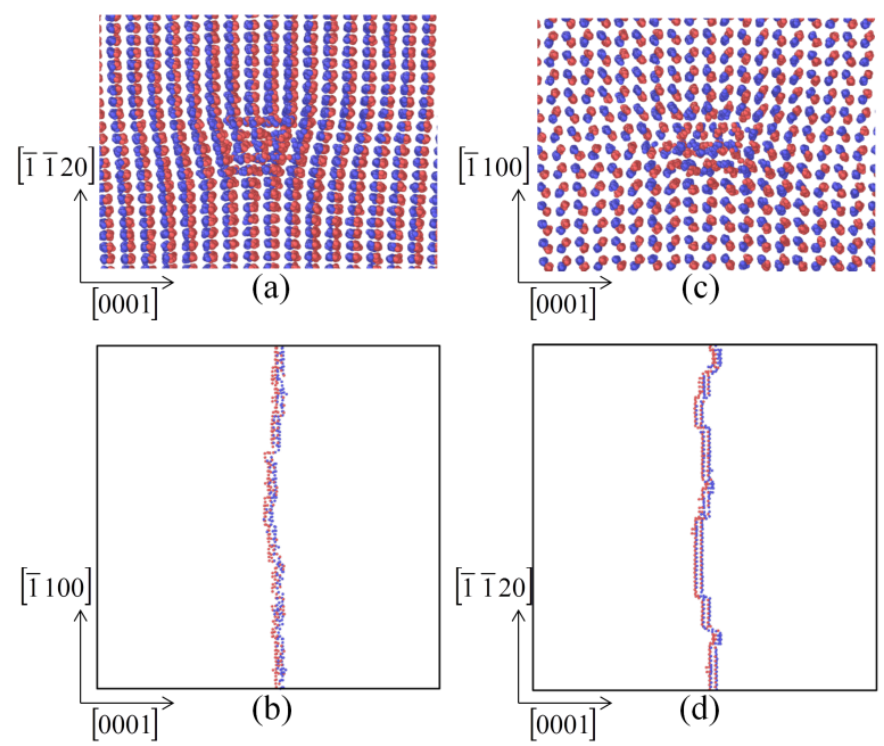

Figure 4 - (a) The core structure of a $(\overline{1} \overline{1} 20)[0001]$ c-type dislocation, (b) the same dislocation looking down on the glide plane, with crystallographic directions as indicated. (c) and (d) are the same for a $(\overline{1} 100)[0001] c$-type dislocation. 
The author regrets this error.

\section{Reference}

N. Scott Weingarten (2015). Dislocation Mobilities in GaN from Molecular Dynamics Simulations. MRS Proceedings, 1741, mrsf14-1741-aa01-03, doi:10.1557/opl.2015.25. 